\title{
UNA APROXIMACIÓN AL MUNDO DEL DINERO EN EL MADRID ISABELINO: EL BANCO DE ECONOMÍAS ${ }^{1}$
}

\author{
por \\ JOSÉ CARLOS RUEDA LAFFOND \\ Universidad Complutense de Madrid.
}

RESUMEN: Este trabajo dirige su atención al fenómeno de las cajas de ahorro privadas constituidas en Madrid durante los años sesenta del siglo XIX y, en especial, a una de las entidades más significativas: el Banco de Economias. Pretendemos aproximarnos al estrato intermedio del incipiente sistema bancario español de aquellas fechas. Un estrato donde también se encuentran sociedades de seguros mutuos o banqueros, prestamistas y comerciantes particulares capaces de componer una red abierta a la captación del aborro local y al interés de otras sociedades de crédito situadas en la cúspide bancaria. De este modo centramos nuestro interés en los rasgos genéricos de tales establecimientos y en las lineas particulares descritas por el Banco de Economias, desde su constitución èn 1860 basta su crisis y liquidación durante los años del Sexenio Democrático.

PALABRAS CLAVE: Historia social. Historia financiera. Madrid. Siglo XIX. Bancos y banqueros.

ABSTRACT: This article directs its attention to the phenomenon of private savings banks constituted in Madrid during the 1860s, especially to one of the most significant: the Banco de Economias. It intends to approach the mid-level of the budding banking system at that time, a level where you can find mutual insurance societies, bankers, moneylenders and other private capitalists, capable of making a network open to the adquisition of the local savings and the interest of other iredit societies wich are situated at the apex of the banking world. The aim of this article is therefore to examine the generic characteristics of these establishments, and the particular qualities of the Banco de Economias, from its launch in 1860 until its crisis and disappearance during the years of "Sexenio Democráticon.

KEY WORDS: Social History. Financial History. Madrid. 19th century. Banks and bankers.

1 Este trabajo forma parte de un proyecto financiado por la Fundación Caja de Madrid dirigido al estudio del préstamo y el alorro en el Madrid de la segunda mitad del siglo XIX. Agradezco las observaciones aquí vertidas planteadas por el profesor Ángel Bahamonde.

Hipania, JVIII/2, núm. 199 (1998) 607-623 


\section{INTRODUCCIÓN. ALGUNOS RASGOS DE LA PIRÁMIDE DE LAS FINANZAS A MEDIADOS DEL SIGLO XIX}

No es exagerado señalar que los años centrales del siglo XIX, y especialmente la fecha de 1856, suponen el telón de fondo para la maduración del primer tejido financiero de la España contemporánea. No sólo asistimos a la definitiva concreción de una banca nacional con la constitución del Banco de España a partir de los cimientos puestos, setenta y cinco años, antes por el Banco de San Carlos y, desde 1829, por el de San Fernando. La combinación de las perspectivas abiertas por el negocio ferroviario, las propias necesidades - y carencias- de la financiación del Estado isabelino y la legislación sobre sociedades de crédito promovida durante el Bienio Progresista animaron la multiplicación de establecimientos, bien conocidos, como el Crédito Mobiliario Español, la Sociedad Española Mercantil e Industrial o la Compañia General de Crédito ${ }^{2}$.

Como es sabido la constitución de tales entidades se identificaba con un abanico de actividades entre las que destacaba la construcción de diversas líneas ferreas (Ferrocarril del Norte; Caminos de Hierro de Madrid, Zaragoza y Alicante; Compañía del Ferrocarril de Sevilla, Jerez y Cádiz), además de otros negocios, como la explotación de minas, la producción de gas o la constitución de sociedades de seguros. Asimismo se definieron como parte indispensable para garantizat el crédito al Estado, prosiguiendo y mejorando los mecanismos de financiación ensayados durante la primera mitad del siglo (proceso desamortizador, recepción de capital extranjero). Y, por fin, tanto las necesidades de capital como los límites de la tesponsabilidad juridica de estas entidades se vieron favorecidas por un marco legal que regulaba su constitución como sociedades anónimas 3 .

Efecto significativo de este proceso fue el de la consagración de Madrid como capital del mercado nacional y de las finanzas. Junto a la centralidad política, garantizada durante el siglo XVIII, se establecieron nuevos contenidos económicos y administrativos -inherentes a la configuración del Estado liberal-- sobre el espacio madrileño. La sanción de la capitalidad coexistió, sin embargo, con la persistencia de un mundo más estrecho, relacionado con la sociedad y la economía tradicionales de la ciudad. No es exagerado apuntar, pues, que desde mediados de siglo, convivió una realidad dual en lo económico y en lo social. Una esfera dinámica, abierta al resto del mercado peninsular gracias a su papel como nudo de comunicaciones, eje del entramado financiero,

2 Sobre este tema continua como obra fundamental de consulta el trabajo de G. TORT'ELLA, Las orígenes del capitalismo en España. Banca, industria y ferrocarriles, Madrid, 1973. Podemos citar también otros estudios que dan luz sobre diversos aspectos concretos, como el ditigido por M. ARTOLA, Los ferrocarriles en España, 1844-1933, Madrid, 1978, o el ensayo sobre las elites financieras propuesto por A. OTAZU, Los Rothschild en España, 1820-1850, Madrid, 1989.

3 Marco legal que representa el primer paso hacia la liberalización de la reglamentación sobre sociedades mercantiles contenida en el Código de Comercio de 1829, a pesar del interés de la legislación de 1856 , únicamente circunscrito a la esfera de las finanzas y las obras públicas. Sobre esta cuestión, G. TORTELLA, «El principio de responsabilidad limitada y el desarrollo industrial en España, 1829-1869), en Moneda y Crédito, 3, 1968, págs. 69-84.

Hispania, LVIIJ/2, núm. 199 (1998) 607-623 
centro bursátil y punto de reunión de los más privilegiados espacios de sociabilidad. Y otra mucho más estática, volcada al consumo de la localidad y con una demanda de bienes y servicios muy limitada ${ }^{4}$.

Dentro del escenario financiero concretado a mediados de los años cincuenta algunos bancos de emisión o sociedades de crédito alcanzaron una re-presentativa significación territoriat fue el caso de la Catalana General de Crédito (1856), el Banco de Sevilla (1857), el de Zaragoza (1857) o la Sociedad Valenciana de Crédito y Fomento (1859). En Madrid, la cúspide del mundo del dineto fue ocupada, en cambio, por el banco nacional, por las tres sociedades antedichas ligadas al capital francés y por otros establecimientos, también interesados en las colocaciones extramuros a la ciudad, como la Sociedad General Española de Descuentos (1859), el Crédito Ibérico (1863), la Sociedad Española de Crédito (1863) o la Compañía General de Crédito, Depósitos y Fomento (1864).

Con una mayor imbricación con el ámbito local se articularon otros mecanismos canalizadores del ahorro y del préstamo a partir de una sucesión de estratos que fue común para otras poblaciones españolas ${ }^{5}$ : en su base se situaba buena parte del préstamo volcado, en mayor o menor grado, a una clientela popular y a prácticas usurarias; al tiempo, también el préstamo prendario con el que operaba el Monte de Piedad. En sus estratos intermedios se localizaba un abigarrado mosaico de particulares y entidades. En él se incluían tanto los prestamistas que cubrian la demanda de dinero requerida por las elites o las clases medias ${ }^{6}$, como los comerizantes capitalistas, sin duda verdaderos protagonistas del sistema bancario español dada su dispersión, abundancia y capacidad de intermediación ${ }^{7}$. Asimismo, en este nivel intermedio de la trama financiera se agrupaban los numerosos establecimientos, organizados en forma de sociedades comanditarias, colectivas y uaccidentales de cuenta en participacióny, que se articularon como compañias de seguros de sistema

4 Como propuesta, esencialmente geográfica, para interpretar la capitalidad económica y de servicios de Madrid, SANZ GARCÍA, Madrid, ¿Capital del capital? Contribución a la geografia urbana y a las funciones geoeconómicar de la Villa y Corte, Madrid, 1975. La cuestión de la dualidad como uno de los ejes para explicar la realidad madrileña durante la segunda mitad del siglo XIX, en A. BAHAMONDE y L. E. OTERO, «Quietud y cambio en el Madrid de la Restauración», en A. Bahamonde y L. E. Otero (eds), La sociedad madrileña durante la Restauración, 1876-1931, Madrid, 1989, Vol. I, paigs. 21-26.

5 Véase, por ejemplo, el estudio de M. TrroS, Crédito y aborro en Granada en el siglo XIX, Granada, 1978.

6 Sobre el mundo del préstamo madrileño, J. A. MAR'IínEZ ANDALUZ, «Préstamo privado y elites en el Madrid isabelinon, en A. Bahamonde y L. E. Otero (eds.), Madrid en la sociedad del siglo XIX, Madrid, 1986, Vol. I, págs. 492-504; A. BAHAMONDE, «La crisis de la vieja nobleza y los prestamistas madrileños", en Estudios Históricos, Madrid, 1990, Vol. II, págs. 363-381; y J. C. RUEDA, «Préstamo y finanzas durante la segunda mitad del siglo XIX: una aproximación a la figura del los Urquijom, en Historia Contemporánea, 13-14, 1996, págs. 297-322.

7 J. R. GARCÍA LÓPEZ, (Banqueros y comerciantes banqueros, clave oculta del funcionamiento del sistema bancario español del siglo XIX», en Moneday Crédito, 175, 1985, págs. 59-85; y «El sistema bancatio español del siglo XIX: ¿Una estructura dual? Nuevos planteamientos y nuevas propuestas", en Revista de Historia Económica, 1, 1989, págs. 111-113. 
mutuo (tontinas) ${ }^{8}$ o como cajas privadas de ahorro e imposición.

A la sombra de la coyuntura expansiva abierta en torno a 1856 se multiplicó este último tipo de negocios. Cajas y tontinas formaton un abanico de entidades ligado a una trama de medianos y pequeños impositores, atraídos por las promesas de rentabilidad y por una incesante publicidad que figuró en muchos medios de la época. Sus colocaciones se guiaron al mundo de la ciudad, al participar en la promoción inmobiliaria planteada a partir del proyecto del Ensanche. Pero también se presentaron como elementos primordiales para la financiación de la Deuda, y aglutinaton un ahorro en parte canalizado hacia la banca dedicada a las operaciones de crédito al Estado o la financiación de las compañías ferroviatias. Esta orientación, supeditada a la cotización en Bolsa de los títulos públicos y a la evolución de las grandes sociedades, fue la que explicó en buena medida la quiebra de todos estos negocios a partir de 1866.

El objeto de este trabajo se dirige al fenómeno específico de las cajas de imposición y, en especial, a una de las entidades más significativas: el Banco de Economías. Pretendemos aproximarnos a ese estrato intermedio del mundo del dinero en Madrid a mediados del siglo XIX, abierto a la captación del ahorto local y al interés de otras sociedades de crédito que componen ya la cúspide bancaria. Atenderemos, así, a los rasgos característicos de estos negocios y a la trayectoria descrita por este Banco, desde su constitución en 1860, hasta su crisis y liquidación durante los años del Sexenio democrático. Desgraciadamente la documentación sobre el Banco de Economías, y sobre el conjunto formado por estos negocios, es limitada. Si bien su proyección pública se basó, en buena medida, en esa incesante publicidad en prensa, sus cuentas públicas deben abordarse con cautela y ofrecen importantes lagunas. El contraste de esta información con otras fuentes puntuales - por ejemplo, las escrituras suscritas ante notario- ayudará sin duda a completar el perfil todavía impreciso de este tipo de compañías.

\section{LAS CAJAS DE IMPOSICIÓN}

No disponemos de una relación exhaustiva de las cajas de imposición abiertas en Madrid a partir de 1856. El cuadro presentado no pretende sino ofrecer una primeta nómina, apuntando el auge coyuntural de tales establecimientos,

$\$$ La denominación provenía del apellido del banquero italiano Lorenzo Tonti. Estas sociedades se presentaban como kasociaciones de personas que se obligaban bajo pactos comunes y por un tiempo determinado a entregar al gestor las sumas convenidas en sus correspondientes contratos para que las inviertiese en objetos determinados, acumulase los intereses y los repartiese en época de liquidacións. El contrato de seguro contemplaba hasta tres personas: el suscriptor que contrataba el seguro, el asegurado y el asociado —en provecho del cual también podia hacerse la imposición-. La vida del asegurado era la clave del negocio. Si éste motía antes de haber concluido el plazo de suscripción el suscriptor perdia, a favor del resto de asegurados vivos, capital, intereses y beneficios. Para el funcionamiento de estas entidades, véase el trabajo firmado por Luis GIL MARCONELL incluido en la versión española de la obra de E. REBOUL, Estudios sobre seguros, Madrid, 1865. El análisis más completo de las mismas en $\mathrm{A}$. BAILMONDE, El borizonte económico de la burguesía madriteña. Madrid, 1856-1866, Madrid, 1980, págs. 138-171.

Hi.punia, LVIII/2, núm. 199 (1998) 607-623 
los intereses previstos en sus respectivos estatutos y la importancia del volumen de ingresos que llegaron a manejar en la década de los sesenta".

CuADRo I. CAJAS DE IMPOSICIÓN CONSTITUMDAS EN MADRID, 1860-1864

\begin{tabular}{|l|l|c|c|}
\hline \multicolumn{1}{|c|}{ Denominación } & Año & Intereses (1) & Ingresos (2) \\
\hline A la Onza de Oro & 1864 & $7-18 \%$ & $0,6(\mathrm{~T}, 1864)$ \\
Ancora Territorial y Mercantil & 1864 & - & $5,1(\mathrm{~T}, 1865)$ \\
La Beneficiosa & 1861 & - & $21,9(\mathrm{I}, 1862)$ \\
La Bienhechora & 1862 & $18-25 \%$ & - \\
Bco. de Economías & 1860 & $\mathrm{~V}$ & $44,4(\mathrm{~T}, 1863)$ \\
Bco. Nacional de Fomento & 1862 & $\mathrm{~V}$ & $18,7(\mathrm{~T}, 1863)$ \\
Bco. Peninsular Hipotecario & 1862 & $6-13 \%$ & $29,4(\mathrm{~T}, 1862)$ \\
Bco. de Previsión & 1862 & $9,38 \%$ & $22,5(\mathrm{~T}, 1864)$ \\
Bco. de Propietarios & 1861 & $\mathrm{~V}$ & - \\
Caja Gral. de Economías & 1864 & $\mathrm{~V}$ & 12 \\
Caja Gral. de Inposiciones y Descuentos & 1862 & $14 \%$ & - \\
Caja de Previsión & 1862 & $\mathrm{~T}, 1864)$ \\
Caja Univ. de Alıorros & 1864 & $6-15 \%$ & $1,1(\mathrm{~T}, 1864)$ \\
Centro Industrial y Mercantil & 1864 & $12-25 \%$ & - \\
La Confianza & 1863 & $\mathrm{~V}$ & - \\
Crédito Mercantil e Industrial & 1863 & $12 \%$ & $9,7(\mathrm{~T}, 1864)$ \\
Crédito Territorial Español & 1862 & - & $8,4(\mathrm{~T}, 1863)$ \\
La Previsora & 1862 & $12-15 \%$ & $3,4(\mathrm{~T}, 1864)$ \\
La Probidad & 1862 & $9-13 \%$ & - \\
La Protectora & 1861 & $\mathrm{~V}$ & - \\
Tesoro de Madrid & 1863 & - & $28,3(\mathrm{~T}, 1865)$ \\
\hline
\end{tabular}

(1): V: Intereses variables, según sean las utilidades obtenidas en cada ejercicio.

(2): Ingresos en millones de reales-vellón. T: Ingresos totales en el año citado; I: Ingresos por imposiciones en el año citado.

Fuente: Estatutos y reseĩas de prensa de las sociedades citadas.

El desarrollo de las cajas debe establecerse en un estrecho lapso de tiempo: el septenio 1860-66. Así como su constitución coincide en el tiempo, concentrándose entre los años 1861-64, todas estas entidades sufren también con idénticos tesultados los efectos de la crisis de 1866. A partir de aquella fecha se sucederán las declaraciones de quiebra y los procesos de liquidación que, con frecuencia, se prolongan hasta bien entrada la década de los setenta.

Una primera dificultad para el estudio de las cajas de imposición es el referido a la estimación del volumen total de dinero manejado. Como referencia compatativa debe apuntarse que, en el caso de las tontinas, las tres entidades

9 Relación que puede ampliarse con otros nombres: Banco de Crédito, Banco de Crédito Hipotecario, Caja Universal de Capitales, Casa-Banca de Aaduid, Casa de consignación de capitales, La Edificadona, La Española, Gran Centro de Contratación, La Propiedad Españoh, La Providencial o ha Valenciana. 
más significativas (La Titular, el Montepío Universal y La Peninsular) llegaron a negociar entre 1857 y 1862 alrededor de 700 millones de reales efectivos en títulos de la Deuda. Gil Marconell estimó, por su parte, que a la altura de 1865 el conjunto de estas entidades había llegado a retirar cerca de dos mil millones en títulos del tres por ciento consolidado y diferido ${ }^{10}$. El monto manejado por las cajas fue, sin duda, muy inferior, aunque centrándonos en los meses de mayor auge - en torno a los años 1863-1865 - podrían estimatse unos ingresos efectivos conjuntos posiblemente superiores a los 250 millones de reales.

Se ha indicado que una de las principales coincidencias entre las sociedades de seguros mutuos y las cajas de imposición fue su similar forma jurídica. Estas compañías adoptaron siempre las modalidades de sociedades mutuas, comanditarias o colectivas ". Bajo estas fórmulas se ocultaba, no obstante, la inexistencia de una efectiva razón social por parte de la compañia y sus promotores. Dicha responsabilidad quedaba sustituida por la idea imprecisa de "garantía administrativa» - la derivada de la existencia de un capital depositado-, dado el infrecuente desembolso efectivo de una fianza proporcional en el Banco de España o en la Caja General de Depósitos ${ }^{12}$.

Tontinas y cajas se presentaron inspiradas bajo una misma justificación: los efectos moralizadores y socialmente rentables del ahorro. Su público se localizaba con preferencia entre los medianos y pequeños impositores, proponiendo unos intereses a medio plazo que podían alcanzar entre un quince y un veinticinco por ciento (Cuadro I). El capital impuesto y sus intereses acumulados se podrían dirigir a aspectos tan variopintos como la redención de quintas, la formación de dotes, la constitución de rentas o el seguro vitalicio ${ }^{13}$.

El perfil del impositor o el suscriptor puede definirse a partir de las nóminas presentadas por La Tutelar. En la relación publicada en 1861 se recogen los nombres de destacados miembros de la elite madrileña como el Duque de Alba (suscriptor de 160.000 reales efectivos), el Conde de Almodóvar (100.000),

10 E. REBoul, Ob. cit., págs. 164165.

11 En el caso de las cajas sus negocios se presentaron también bajo diversos nombres: cajas de imposición, cajas de ahorro, cajas universales, cajas de capitales, cajas generales, cajas de fomento, montes de previsión, sociedades para colocación de capitales, formación de capitales o bancos. Esta última denominación era teóricamente incorrecta, al reservarse tan sólo a los establecimientos de emisión o a las sociedades anónimas de crédito.

12 El banquero madrileño Francisco Vargas Machuca recogió en un opúsculo, no obstante, una crítica a las sociedades anónimas de crédito que coincidía con la filosofia difundida por cajas y tontinas: «las sociedades anónimas no eran tesponsables ante ei público. Y, con frecuencia, esa senda ha conducido al derrumbadero a algunas sociedades que han medrado casi fabulosamente en la abundancia para venit después a morir sufriendo una completa derrotà. VARGAS MACHUCA (1864), pág. 5. Por su parte, estas entidades aseguraron que los imponentes eran, en realidad, asociados al afirmar que una vez concluido el plazo de las imposiciones se les entregaría el capital, los intereses acumulados y una parte alicuota de los beneficios de la compañía.

13 Superaton con creces, pues, el marco de meras cajas para tedención del servicio militar, tal y como fueron interpretadas en su día por N. SALES DE BOHIGAS, «Sociedades de seguros contra las quintas (1865-1868)", en La revolución de 1868: Historia, pensamiento y literatura, Nueva York, 1970, págs. 109-124.

Hispania, LVIII/2, nü. 199 (1998) 607-623 
Paulino Uhagón (275.000) o Nazario Carriquiri (90.000). Sin embargo, de las 1.139 suscripciones existentes en aquella fecha sólo 37 superaban los 100.000 reales, 100 se situaban entre los 99.999 y los 50.000 reales, 195 entre los 49.999 y los $25.000,180$ entre los 24.999 y los 15.000 , y 627 se referían a suscripciones de menos de 14.999 reales ${ }^{14}$.

Por el contrario, los fundadores y gestores se localizaron entre los mayores impositores. También los presentados como Consejos de Vigilancia, que recogían con insistencia a "personalidades de reconocido prestigio»: propietarios, títulos nobiliarios, prohombres de la elite mercantil, personajes de renombre intelectual y literario o políticos. Un ejemplo paradigmático lo encontratiamos en el Banco de Propietarios. Esta caja de imposición y préstamos, constituida en 1861, contó en su Consejo con nombres tan representativos como los de Eduardo Chao, Estanislao Figueras, José Abascal, el Marqués de Perales o Manuel Ruiz Zorrilla ${ }^{15}$.

Las colocaciones de las sociedades de seguros mutuos y de las cajas de imposición ofrecieron distinto perfil. Salvo en el ejemplo de La Peninsular, centrada en el negocio inmobiliario, la práctica totalidad de las tontinas dirigieron su atención a la adquisición de títulos de la Deuda ${ }^{16}$. Por el contratio las operaciones previstas por las cajas de imposición fueron mucho más amplias. Ocasionalmente negociaron valores públicos, aunque dentro de un abanico de colocaciones donde se podían incluir descuentos y préstamos, giros, representación de otras sociedades o, fundamentalmente, compra-venta de terrenos e inmuebles y préstamos hipotecarios ${ }^{17}$. Así, por ejemplo, La Beneficiosa planteó como su única colocación desde 1861 los préstamos a la asociación de créditos comerciales El Manantial de Crédito. La desastrosa gestión de esta entidad aconsejó la participación, a partir de 1863, en la sociedad comanditaria Banco Hipotecario de España (Casa Rózpide y Compañía), constituida en aquel año con un capital efectivo de diez millones de reales con el objeto de participar en el negocio inmobiliatio ${ }^{18}$.

Muestra de una red societaria compleja y diversificada es la presentada por los negocios promovidos por el activísimo editor Francisco de Paula y Mellado.

14 La Tutelar, Lista general alfabética de las suscripciones autorizadas por la Compaña correspondientes a esta lacalidad de Madrid basta el día 1 de junio de 1861, Madrid, 1861.

15 Banco de Propietarios, Asociación para préstamos, giros, descuentos e imposiciones. Estatutos, Madrid, 1862.

16 Tal y como afirma Ángel BAHAMONDr:, en teoria La Peninsular era una más entre las sociedades de seguros mutuos aunque en la práctica tesultó la sociedad inmobiliaria más importante en el Madrid de los años sesenta. A. BALIAMONDE, «Pascual Madoz y la modernización de la ciudad de Madrid: La Peninsular, empresa inmobiliaria; 1861-1883", en J. L. García Delgado (ed.), Las ciudades en la modernización de España. Los decenios interseculares, Madrid, 1992, págs. 379-404.

17 El ya citado Francisco Vargas Machuca inclusó planteó el ampliar las colocaciones de su CasaBanca hasta la constitución de un Banco Agricola y la kemisión de un papel que, sin relacionarse con el papel-moneda, facilitase los cambios, interponiéndose a las crisis monetariasn, $O b$. $a t$, págs. 4-5.

18 La Beneficiosa, Asociación mutua para colocar economias y capitales, Madrid, 1863; El Manantial de Crédito, Junta General de los socios... celebrada el 2 de marzo de 1861, Madrid, 1861. 
En este caso las cajas forman parte de un proyecto empresarial mucho más vasto, iniciado en los años cuarenta a partir de la creación de un primer establecimiento tipográfico. Esta imprenta y la responsabilidad personal del fundador se constituyeron en las garantías de otras compañías, como La Biblioteca Española (fundada en 1852 con un capital nominal de dos millones de reales), la Caja y Seguro de Quintas (1857) y la Caja del Comercio y la Industria (1858, con un capital nominal de ocho millones de reales) ${ }^{19}$.

Estas sociedades quedaron incorporadas en 1864 al Banco Industrial y Mercantil dirigido por Mellado. El Banco se implicó, desde entonces y hasta su quiebra en 1866, en actividades tan diversas como la edición y comercialización de publicaciones, la apertura de una librería en París, la explotación de siete minas de cobre, plomo y carbón, o la creación de una entidad filial (La Herculana), constituida con el objeto de construir un canal y un ferrocarril en la comarca de Sierra Almagrera. A ello debe sumarse el negocio de la redención en metálico del servicio militar, por medio de la caja para el seguro de quintas. La Caja Universal de Ahorros, constituida también en 1864, emprendió, por su parte, la compra-venta de inmuebles en Madrid y operaciones de préstamo a la Caja de Seguros ${ }^{20}$.

\section{EL BANCO DE ECONOMÍAS, 1860-1876}

\subsection{Los años de auge, $1860-1864$}

En este escenario el Banco de Economías ocupó, sin duda, un papel relevante, tanto por su imbricación con el ahorro local como por su tápida vinculación con el Banco de Madrid, sociedad de crédito de alcance peninsular. Fundado en 1860 por Diego Montaut y Cayetano Ruíz de Ahumada como caja de ahortos para formación de capitales y como depósito de fondos a plazo, a finales de aquel año el Banco de Economías sumaba ya unos ingresos de 125.898 reales por imposiciones, cuentas corrientes y otros depósitos. Doce meses después esta cantidad se incrementó hasta los 11,7 millones, en mayo de 1862 alcanzó 21’5 millones y en noviembre de 1863 llegó hasta los 44,4. El reintegro a impositores, depositantes y cuentacorrentistas se desarrolló durante este período en paralelo al auge de la entidad: de los 1,7 millones devueltos a los impositores a lo largo de 1861 se pasó a 18'6 en noviembre de 1863. En la última fecha la cantidad de efectivo restituido alcanzó los 24,5 millones de reales

19 La Biblioteca Española se configuró como sociedad editorial. En 1860 afirmó que había obtenido unos beneficios del 74 por ciento sobre el capital impuesto. La Caja y Seguro de Quintas se encaminó a dos actividades complementarias: la formación de capitales y de rentas y la redención del servicio militar por medio de seguros mutuos. Por fin, la Caja del Comercio tuvo como objeto principal la adquisición de varias explotaciones mineras. F. de P. MIBLLADO, Almanaque-Catálogo. Album pintoresco del Establecimiento Tipográfico as Mellado, Madrid, 1800; y Caja de Segura. del Establecimiento de Mellado, Madrid, 1857.

20 banco Industrial y Mercantil, Memorias correspondientes a 1865 y 1867.

Mitpania, LV1IL/2, núm. 199 (1998) 607-623 
(Cuadro II) ${ }^{21}$. Los intereses aplicados por el Banco fueron variables, en virtud de los plazos de imposición — de 6 a 18 meses-, las cantidades impuestas - desde diez reales-y de las utilidades obtenidas. Entre mayo de 1861 y mayo de 1862 distribuyó, como media, un interés efectivo del uno por ciento mensual, resultando entre las mismas fechas una utilidad proporcional del $13^{\prime} 96^{22}$.

\section{CUADRo II. EVOLUCIÓN DEL VOLUMEN DE INGRESOS Y SAIIDAS DEL BANCO DE ECONOMIAS; NOVIEMBRE DE 1860-NOVIEMBRE DE 1863 (EN rs.vn.)}

\begin{tabular}{|l|c|c|c|c|}
\hline & Imposiciones & $\begin{array}{c}\text { Cuentas } \\
\text { Corrientes }\end{array}$ & $\begin{array}{c}\text { Total } \\
\text { Ingresos }\end{array}$ & $\begin{array}{c}\text { TotaI } \\
\text { Salidas }\end{array}$ \\
\hline Nov. 1860 & 125.898 & - & 125.898 & - \\
\hline h. Nov. 1861 & 9.531 .114 & 1.714 .619 & 11.758 .514 & 3.512 .674 \\
\hline h. Nov. 1862 & 18.200 .981 & 5.666 .257 & 26.043 .826 & 13.218 .826 \\
\hline h. Nov. 1863 & 35.252 .724 & 4.746 .249 & 44.436 .189 & 24.538 .515 \\
\hline
\end{tabular}

Fuente: Memorias de los años citados.

Es difícil, por su parte, establecer la identidad de los impositores al no existir telaciones completas de los mismos. Sin embargo, el monto de las entregas efectuadas en 1862 perfiló una distribución en la que eran preponderantes «las pequeñas economías incapaces de producir beneficio alguno aisladamente»: de un total de 4.667 imposiciones, 2.456 lo eran por una cantidad inferior a los 100 reales, 1.329 oscilaban entre 100 y $5.000,473$ lo eran por una cuantía entre 5.000 y 10.000 , y tan sólo 409 por más de 10.000 reales ${ }^{23}$.

Las operaciones emprendidas por la sociedad fueron presentadas en los Estatutos de 1860 bajo la idea genérica de "aquellas inversiones más ventajosas para los socios». Estas se concretaton en tres capitulos fundamentales:

- Préstamos a una entidad filial (la Unión Industrial), creada en enero de 1861 por los mismos responsables del Banco bajo la fórmula de responsabilidad mancomunada. Su objeto era la provisión de créditos para sufragar establecimientos comerciales y pequeñas industrias.

- La adquisición de valores públicos, esencialmente títulos de la Deuda Pública al tres por ciento.

- La compra-venta de fincas rústicas y urbanas y la construcción de inmuebles.

21 Banco de Economías, Juntas Generales. Extractos del Acta y memoria de la administración, correspondientes a 1862,1863 y 1864.

22 La Correspondencia de España, 30-VIII-1862, p. 4.

23 El entrecomillado en Banco de Economías, Junta General.. correspondiente a 1863, pág. 19. El reparto de los impositores en Junta General... de 1862, pág. 15. 
CUADRo III. EVOLUCIÓN DEL. BALANCE DEL BANCO DE ECONOMÍAS; 1861-1864, (en rs.vn.)

\begin{tabular}{|c|c|c|c|c|}
\hline \multicolumn{5}{|c|}{ ACTIVo } \\
\hline & 1861 & 1862 & 1863 & 1864 \\
\hline Caja & 324.950 & 182.282 & 204.397 & 483.281 \\
\hline Bco. España & - & 20.000 & - & - \\
\hline Caja Gral. Dep. & - & 44.544 & 2.206 .486 & 7.280 \\
\hline Agentes & 201.885 & 650.816 & 2.883 .540 & 2.385 .339 \\
\hline Mercaderias & 596 & 23.863 & - & - \\
\hline Ctas. varios & - & 281.519 & 6.628 .107 & 1.768 .507 \\
\hline Valores públ. & 1.236 .293 & 1.637 .324 & 1.262 .792 & 445.039 \\
\hline Cartera & 7.927 .494 & 18.966 .248 & 28.799 .956 & 37.500 .169 \\
\hline Garantías & - & - & - & 1.412 .000 \\
\hline Construcciones & $\leftarrow$ & - & - & 1.371 .050 \\
\hline Sucursales & - & - & - & 2.037 .303 \\
\hline \multicolumn{5}{|c|}{ PASIVO } \\
\hline Socios & 9.567 .504 & 21.024 .573 & 41.164 .703 & 45.190 .531 \\
\hline Depósitos vlt. & 一 & 244.400 & - & 15.158 \\
\hline Efectos a pagar & 91.545 & 137.907 & 241.871 & 584.910 \\
\hline Ctas. corrs. & 29.287 & 136.840 & - & - \\
\hline Bco. de Madrid & - & - & 116.690 & 613.732 \\
\hline Ganancias y Pérdidas & 2.882 & 262.876 & 462.014 & 613.732 \\
\hline \multirow[t]{2}{*}{ Inmuebles } & - & - & - & 486.635 \\
\hline & 9.691 .218 & 21.806 .596 & 41.985 .278 & 47.409 .968 \\
\hline
\end{tabular}

Fuente: Memorias de los años citados.

No obstante, según se desprende de los balances publicados hasta 1865 , ha de señalarse la parquedad de dichas colocaciones, especialmente en lo referido a la tardía promoción inmobiliaria (Cuadro III). A tenor de estas cuentas, el rasgo más significativo fue la relevancia alcanzada por su cartera de valores. Según la Memoria correspondiente a 1863 , en aquella fecha se habían llevado a cabo 4.567 operaciones de descuento, con un movimiento total de 81 millones de reales, y 4.508 negociaciones sobre letras por un monto de 49 millones. Por el contratio, la adquisición y venta de inmuebles no se reflejó por vez primera en el activo hasta las cuentas correspondientes a 1864 , con una partida de apenas 1,3 millones de reales. Tampoco la Unión Industrial llegó a convertirse en una entidad significativa. Con un capital de poco más de cuatro millones de reales

Hipqunia, LVIJI/2, núm. 199 (1998) 607-623 
y 185 socios en 1862, se vio obligada a negociar sus efectos sometida a baísimos tipos de interés, lo que coadyuvó a una cuenta de resultados negativa desde aquella fecha.

En virtud de la escritura pública otorgada en enero de 1864 se realizó la cesión de la administración y gerencia del Banco de Economías a favor de la recién creada Sociedad de Crédito y Fomento Banco de Madrid ${ }^{24}$. Esta operación se justificó desde el Consejo de Vigilancia de la caja como inevitable para asegurar la confianza de nuevos impositores y facilitar la realización de los valores de la sociedad, poniendo a cubierto las posibles obligaciones ordinarias o extraordinarias que contrayese la entidad. Ya a inicios de 1862 se habían producido las primeras señales de crisis en el entramado financiero, a raíz de la suspensión de pagos en varios establecimientos madrileños. Y si bien el resultado global de la caja era satisfactorio, ésta se vio obligada a teducir el monto de sus colocaciones, cubrir varios reembolsos extraordinarios y aplazar operaciones de cobros sobre imposiciones vencidas.

Aunque el traspaso se acompañó con la participación de tesponsables e impositores del Banco de Economías en la nueva compañía ${ }^{25}$, la transferencia de los derechos de getencia convertía, en puridad, al Banco de Madrid en banquero de la caja de imposición. A partir de esa fecha la sociedad de crédito se responsabilizó estatutariamente de las futuras colocaciones de capital y de la elaboración del balance general ${ }^{26}$. Los cargos de director general y de administrador de la sociedad de crédito fueron cubiertos a partir de mediados de 1864 por los fundadores del Banco de Economías, Diego Montaut y Cayetano Ruiz de Ahumada. Sin embargo, la personalidad más destacada de la nueva entidad fue la de su presidente, el activo banquero Nazario Carriquiri, prohombre de las filas moderadas y figura omnipresente en los negocios madrileños. Había participado, en los años cuarenta, en el efimero impulso societario que se saldó con la creación de entidades como La Sociedad de Amigos de la Juventud (caja de redención de quintas), la compañía minera La Realidad, la sociedad La España Industrial o la Sociedad Mercantil Española. Su nombre se encuentra también entre los animadores del Banco de Isabel II ${ }^{27}$. Y, ya en los sesenta, figuraba asimismo en los consejos de otras empresas madrileñas como La Peninsular.

24 El Banco de Madrid dirigió su atención a los negocios ferroviarios. Desde 1864 participó en las líneas de Madrid a Malpartida, de Valencia a la Ribera y de Liria. Asimismo proyectó su conversión en banco de emisión para varias localidades. Sociedad de Crédito y Fomento Banco de Madrid, Reglamento aprobado por el Consejo de Administración, Madrid, 1864.

25 Como consecuencia de una capitalización de beneficios del 21'6 por ciento la caja de imposición recibió un paquete de 3.518 acciones de la sociedad de crédito. Esta participación se vió incrementada indirectamente, dado que la mayoría de las acciones emiticas fueron suscritas, a lo largo de los primeros meses de 1864, por impositores del Banco de Economias.

26 Para el proceso de vinculación con el Banco de Madrid, Banco de Economias, Junta general de socios.. de 1864. Memoria de La Administración y 4. Junta General.. de diciembre de 1864. Esta Memoria incluye los nuevos Estatutos con las modificaciones relativas a administración y gerencia.

27 Para la figura de Carriquiri, A. O'NZU, Ob. cit., espec. págs. 314-315 y 327 y ss. Formaron también parte del consejo del Banco de Madrid el Marqués de San Román, José de Reinas, Lorenzo Guillelmi, Miguel Alvarez Candamo y Aniceto Puig.

Hitpania, LVIII/2, núm. 199 (1098) 607-623 
A pesar de estos cambios el Consejo de Inspección del Banco de Economías se mantuvo estable, respetando los nombres elegidos desde 1860. Este órgano de vigilancia reflejó, como en los casos de otras cajas o sociedades de seguros mutuos, los pirncipios de «calidad social» y ureconocido prestigio» que se estimó debian caracterizar a la instancia más representativa de la compañía. Formaton así parte del consejo nombres como los de el Marqués de Castellanos (senador), Tomás de Liegués y Bardaji (Marqués de Alhama), el Gentilhombre de Cámara de la Reina Juan Bautista Tamarit, los Marqueses de Casa-Arizón y Campo-Santo o los ex-ministros Fernando Corradi y Nicómedes Pastor Díaz.

\subsection{Crisis y liquidación del Banco de Economias}

El bienio 1865-66 supuso el punto de arranque para una crisis general en la economía española. Una crisis bien conocida por la historiografia social y económica que, entre otras consecuencias, provocó la total desaparición de las sociedades de seguros mutuos y de las cajas de imposición constituidas en los años inmediatamente anteriores. Entre los aspectos que explicaron esta sucesión de quiebras incidieron elementos de índole general, como la conclusión del negocio fertoviario, las dificultades en las principales sociedades de crédito y los problemas de la Hacienda Pública ${ }^{28}$. También afectaron otros factores mucho más próximos al escenario madrileño, como fueron el estancamiento y ulterior descenso de los precios manejados en las operaciones inmobiliarias -en especial, en el Ensanche-, el pánico de un buen número de suscriptores e impositores desde 1865 y las contradicciones atrastradas por la administración de estas entidades ${ }^{29}$. En las siguientes líneas repasaremos aquellos elementos más destacados en la crisis del Banco de Economías, extensibles, en buena medida, a otros procesos de liquidación de compañías similares.

En primer término han de señalarse las dificultades iniciales en algunas entidades (la Compañía General de Crédito) y la tendencia a elevar los tipos de descuento, lo que incide negativamente en el papel de intermediador que juega el Banco de Economías. Quiebras como las de la Sociedad General de Descuentos provocan el descubierto de cantidades significativas (más de cinco millones de reales en 1865), a pesar de que tales colocaciones se habían defendido

28 La crisis general de 1868 ha sido abordada desde múltiples perspectivas. Véanse los estudios, ya clásicos, de N. SÁNCHIEZ ALBORNOZ, España bace un siglo. Una economía dual, Madrid, 1968 y Jalones en la modernización de España, Barcelona, 1975. La relación entre la crisis del ferrocarril y el entramado financiero ha sido resaltada por G. Tok'liLJ A en sus Origenes..., págs. 243-292. Para la interpretación de las dificultades en la banca española en el contexto de las crisis fintancieras contemporaneas es especialmente eschrecedor el artículo de P. TEDDE, (Las crisis bancarias en España: una perspectiva históricay, en El sistema financiers en la economia española, Madrid, 1989, págs. 13-33.

29 Para la evolución de los precios en el Ensanche, R. MAS, E/ barrio de Salamanca. Planteamiento y propiedad inmobiliaria en el Ensanche de Madrid, Madrid, 1982. Los rasgos de la crisis en Madrid pueden seguirse en A. BAIAMONDE y J. TORO, Burguesia, especulación y cuestion social en el Matrid del siglo XIX, Madrid, 1978.

IJipatati, LVIII/2, núm. 199 (1998) 607-623 
en años anteriores como muy ventajosas, al estimarse que podían ser rápidamente reducidas a metálico. Por otro lado debe destacarse también que la sucursal del Banco abierta en Valencia en 1864 para practicar operaciones de crédito y descuento con otros establecimientos locales ha aventurado a lo largo del año más de dos millones de reales, bajo un interés anual del 3,2 por ciento, que no llegarán jamás a reponerse ${ }^{30}$.

Desde finales de año se suceden, a su vez, los vencimientos impagados de los tútulos hipotecarios. Como se ha indicado, no es hasta comienzos de 1864 cuando el Banco de Economías inicia la colocación de capitales en terrenos e inmuebles. A partir de esta fecha se adquirieron y vendieron diversas fincas en las calles de Pelayos, Ave María y Olivar (Interior), así como 14.000 metros cuadrados en Chamberi. Tales propiedades, compradas en el momento de mayor expansión de los precios inmobiliarios, se convertirán en parte importante del activo de la entidad, a pesar de sufrir entre 1865 y 1868 una depreciación que podría rondar entre el 30 y el 50 pot ciento de su valor de compra.

Los problemas en las operaciones de descuento, el paulatino derrumbre de los valores públicos y la quiebra de la cadena que aseguraba el flujo de metálico gracias a los préstamos hipotecarios provocaron las primeras dificultades para cubrir los intereses. Después precipitaron la salida masiva de socios y la imposibilidad de devolver las cantidades depositadas. El primer indicador fue la caída de los intereses efectivos, a partir de noviembre de 1864, cuando se devolvió tan sólo una media de setenta céntimos. Desde mediados de año se deterioró también la principal partida de la caja, al romperse la evolución ascendente de los ingresos que pasaron de los 44' 4 millones de reales de 1863 a poco menos de $32^{2} 5$. Estos problemas se vieron agravados, en último término, por las irregularidades de la empresa. Por ejemplo, hasta 1862 no se constituyó el fondo de reserva, que en un principio ni siquiera cubría el cinco por ciento del capital efectivo. En dos meses (noviembre-diciembre de 1864) esta partida disminuyó un trece por ciento para afrontar el pago ordinario de intereses, quedando reducido en marzo de 1865 a tan sólo 169.445 reales.

La crisis del Banco de Economías se agudizó a partir de esa fecha. Por acuerdo adoptado en el mes de diciembre la Junta General de Imponentes declaró al Banco de Madrid dueño de todos los bienes y valores de la caja. A cambio la sociedad de crédito se obligaría a cubrir por sorteo, en un plazo inferior a diez años y bajo un interés efectivo del cinco por ciento anual, los cuarenta millones de reales que se estimaba componían el capítulo conjunto de imposiciones, cuentas corrientes y depósitos impagados, ya fuesen a plazo o voluntarios ${ }^{31}$.

Muy poco se avanzó en este proceso en los siguientes meses. En primer lugar, por los problemas que también arrastraba la sociedad anónima. En segun-

30 Banco de Economías, Junta general celebrada el 22 de mayo de 1864..., págs. 49.

31 Para la evolución detallada de la crisis: Banco de Madrid, La Sociedad de Crédito y Fomento Banco de Madrit a sus accionistas y a los imponentes del antiguo Banco de Economias, Madrid, 1868, y Banco de Economias, Depósitos de fondos con plazos e interes fjo. Caja de Ahorros y formación de capitales, 1 fadrid, 1865. También desde 1868 un grupo de impositores publicaron periódicamente un Boltín. 
do término, por los escollos legales que entorpecieron la liquidación. A pesar del acuerdo suscrito en diciembre de 1865, un nutrido grupo de impositores presentaron varias denuncias exigiendo el reintegro inmediato de sus capitales. Los tribunales dictaton un embargo por valor de veinte millones de reales, inmovilizando un paquete de créditos hipotecarios ya vencidos y otros bienes de la entidad, entre ellos las nueve sucursales que el Banco llegó a tener abiertas en la capital.

La Junta Extraordinaria celebrada en julio de 1867 concluyó, por su parte, con un frontal desacuerdo entre los responsables de la gerencia y la administración y los representantes de los impositores. Aquellos exigieron una representación conjunta de los suscriptores presentes y de los «disidentes» que habían iniciado acciones legales. Estos plantearon a la sociedad de crédito un anticipo inmediato de dos millones de reales. En los meses siguientes se agravó el enfrentamiento entre ambas partes, solicitando la Junta de Vigilancia la declaración de nulidad del acuerdo suscrito en diciembre de 1865. Por dictamen del Consejo de Estado se había estimado que dicho contrato encubría, en realidad, una fusión entre ambas entidades, lo que impediría reconocer el posible papel de acreedores a los antiguos impositores. Por Real Orden de marzo de 1868 se consideró sin efecto aquel convenio, obligándose a la sociedad de crédito a la inmediata transferencia de "valores y pertenencias en litigios a favor de los suscriptores del de Economías.

Es difícil detallar la política desarrollada entre 1866 y 1868 por parte del Banco de Madrid respecto a la liquidación. No obstante, la declaración de quiebra de esta entidad a comienzos de 1870 no hizo sino reflejar las dificultades por las que también atravesó la sociedad anónima. Esta situación explicó el incumplimiento del compromiso suscrito entre ambos establecimientos más allá del abono de los intereses pendientes que correspondían a 1865 y a la primera mitad de 1866.

En cualquier caso, la causa esgrimida por el Banco presidido por Carriquiri para no cubrir el pago a los impositores fue únicamente la de «la oscura situación legal planteada por los disidentes». En un opúsculo justificativo publicado por el Banco de Madrid después de la Real Orden de 1868 se aseguró que la cartera de la caja de imposición no había sufrido ningún quebranto. Sin embargo, en la presentación del Balance elaborado al año siguiente por la Comisión Liquidadora se afirmó que, dadas las desacertadas colocaciones de capital emprendidas por la sociedad anónima, no se había logrado otra cosa que «vaciar la Caja y aumentar los créditos sin garantía». A tales gestiones se añadía también la imposibilidad de ajustar los balances, dado que desde 1865 no se habían hecho públicas las cuentas del Banco y que «se habían extraviado, además, títulos de propiedades hipotecadas, expedientes, pagarés y escrituras de préstamo's ${ }^{32}$.

32 Banco de Madrid, La Sociedad..., págs. 12-15, y Banco de Economias, Acta de la Junta General de Imponentes celebrada el día 2 de enero de 1870, págs. 7-9.

Hipquiá, I,VII]/2, núm. 199 (1998) 607-623 
CUADRO IV. EVOLUCIÓN DEL BALANCE DE LIQUIDACIÓN DEL BANCO DE ECONOMÍAS, DICIEMBRE DE 1869-DICIEMBRE DE 1871 (en rs.vn.)

\begin{tabular}{|c|c|c|c|}
\hline \multicolumn{4}{|c|}{ ACTIVO } \\
\hline & 1869 & 1870 & 1871 \\
\hline Caja & 5.489 & 2.173 & 4.218 \\
\hline Depósitos & 11.081 & 11.081 & 11.081 \\
\hline Descuentos & 492.898 & 471.678 & 456.941 \\
\hline Fianzas & 1.225 & 1.225 & 1.225 \\
\hline Comisión & 16.286 & 16.286 & 16.286 \\
\hline Comisionados & 539.404 & 399.656 & 401.145 \\
\hline Unión Industrial & 22.239 & - & 一 \\
\hline Soc. Gral. Descuentos & 5.186 .802 & 4.186 .724 & 4.705 .408 \\
\hline Banco de Madrid & 16.144 & 一 & 一 \\
\hline Deudotes varios & 2.827 .079 & 2.675 .695 & 1.674 .002 \\
\hline Deudores por pagarés & 1.569 .224 & 1.525 .886 & 1.462 .629 \\
\hline Anticipos & 215.069 & 182.637 & 169.230 \\
\hline Efectos a negociar & 10.038 & 10.038 & 10.038 \\
\hline Valores nominales & 2.757 .979 & 2.693 .797 & 869.496 \\
\hline Sección contenciosa & 24.298 .002 & 23.218 .917 & 21.541 .935 \\
\hline Fincas rústicas & 654.668 & 654.668 & 791.503 \\
\hline Fincas urbanas & 3.714 .673 & 3.691 .417 & 3.600 .687 \\
\hline \multicolumn{4}{|c|}{ PASIVO } \\
\hline Imposiciones & 35.554 .646 & 34.022 .126 & 31.836 .229 \\
\hline Banco de Madrid & 2.143 .652 & - & 一 \\
\hline Acreedores varios & 104.513 & 69.416 & 94.668 \\
\hline Intereses (1866) & 249.538 & 254.883 & 244.090 \\
\hline Comisiones 1868-71 & 3.160 & 1.000 & 3.160 \\
\hline Comisionados & 32.001 & 17.655 & 41.094 \\
\hline Fianzas & 1.560 & 1.260 & 1.260 \\
\hline Garantías en curso ejecutivo & 977.583 & 977.583 & 996.696 \\
\hline Valores nominales & 2.585 .838 & 2.583 .764 & 885.248 \\
\hline Depósitos & 30.675 & 30.675 & 30.675 \\
\hline \multirow[t]{2}{*}{ Ganancias y pérdidas } & 655.170 & 1.783 .516 & 1.583 .416 \\
\hline & 42.338 .336 & 39.741 .878 & 35.715 .824 \\
\hline
\end{tabular}

Fuente: Memorias de Liquidación de los años citados. 
La dificultad para la liquidación del pasivo del Banco de Economías es evidente a la luz de estos balances (Cuadro IV). El grueso del activo se encontraba embargado y pendiente de múltiples decisiones judiciales. Se carecía también de liquidez. A ello se sumaban otras partidas de diversos deudores -entre ellos, la General de Descuentos-- de muy dudosa realización. Otros capítulos se encontraban hipertrofiados, dado que las propiedades urbanas habian sufrido una segura devaluación y que, tal y como apuntó la Junta de Liquidación, no existín prácticamente créditos que ascendiesen a mucho más valor que las propias fincas hipotecadas. Por fin, el pasivo estaba infravalorado, por cuanto no incluía tampoco el volumen total de suscripciones reclamadas ni todos los intereses pendientes.

Las vías de solución fueron, pues, muy limitadas. Resultó, por ejemplo, imposible el realizar en metálico los créditos gravados con una única hipoteca. Otros asuntos, como la dificultad de llegar a un acuerdo conjunto con los impositores «disidentes", no hicieron sino impedir una solución a medio plazo para los $250 \mathrm{im}$ positores todavía asociados, al mantenerse embargado el grueso del activo.

No obstante, a la altura de 1875 los responsables de los bienes de la entidad pudieron anunciar la resolución de 17 de los 42 millones de reales contemplados en el pasivo de 1869. En estos siete años se había logrado la liquidación puntual de algunos créditos con hipotecas insuficientes para cubritlos por medio de sorteos o a cambio de imposiciones del Banco con tipos y precios establecidos a juicio de la Comisión de Liquidación. Asimismo, en 1872 se obtuvieron los presentados como «importantes acuerdos de transacción» con un pequeño grupo de «disidentes» con el fin de desbloquar los embargos: la liquidación de ocho paquetes de imposiciones -que incluían capital, intereses y costas--valorados en 2 ' 6 millones de reales por un precio conjunto de apenas un millón y medio de reales ${ }^{33}$.

Nuevos enfrentamientos entre los impositores pusieron de manifiesto lo oneroso que llegó a ser el proceso de liquidación. Un numeroso grupo de suscriptores presentes en la Junta Estraordinaria de 1876 exigió la dimisión de la Comisión Liquidadora, la subasta de los créditos de probable realización y la distribución a prorrata del resto del activo. Quedando en minoría abandonaron la sala e iniciaron, de nuevo, acciones legales. Este conflicto, reflejado en el Acta de la tumultuosa sesión, supuso el último acto en la historia del Banco de Economías ${ }^{34}$.

\section{CONCLUSIONES}

La evolución y crisis del Banco de Economías presenta unos rasgos similares al del resto de cajas y tontinas constituidas en la década de los sesenta. Es-

33 Banco de Economias: Acta de la Junta.. celebrada en el dia 5 de marzo de 1871; Memoria que la Comisión Liquidadora ba de leer a la Junta General de Imponentes del mismo, convocada para el dia 3 de marzo de 1872; y Acta de la junta... celebrada en los dias 30 de enero y 6 de febrero de 1876.

34 Banco de Economías, $O 6$. cit. Previamente se publicaron varios folletos críticos con la gestión de la Comisión Liquidadora: C. GARCiA OTERO, Refutación de las ofensas que le dirigió D. Adriano Cuniel y Castro, Madrid, 1872; y, especialmente, el anónimo tirulado, Laz en la liquidación del Banto de Economias, Madrid, 1875.

Hig.puna, LVIII/2, nu่m. 199 (1998) (107-623 
tos establecimientos fueron consecuencia del ciclo ecónomico expansivo que acompañó a los últimos años del reinado de Isabel II y que afectó a todo el sistema bancario español. Cajas y tontinas configuraton los estratos intermedios de aquella red. Canalizaron el ahorro de pequeños y medianos suscriptores, y se conviertieron en instrumentos de intermediación indispensables para la contratación de valores públicos, operaciones de préstamo, crédito o descuento y para la promoción inmobiliaria en una urbe que proyectaba su Ensanche.

La precariedad de muchas operaciones —en ocasiones, sin las más mínimas garantias- su identificación (y sometimiento) respecto a otras sociedades anónimas de crédito más ambiciosas, la carencia de un control oficial efectivo y su peculiar estatus jurídico denotaban la debilidad de estas compañías y del propio sistema. No fue extraño entonces que la contracción económica iniciada en 1866 afectase de modo general a todos estos negocios y que no pudiesen superarla. Fueron capaces de constituirse como elementos mercantiles dinámicos en el proceso de modernización -de transición incompleta, en palabras de Gabriel Tortella - del sistema bancario, pero también es cierto que su inestabilidad reflejó la fragilidad - y el interés especulativo- dominante en estos decenios.

El Banco de Economías es un ejemplo emblemático en este escenario. Llegó a manejar un importante volumen de ingresos y planteó, en un comienzo, un abanico de colocaciones diversificado. Las dificultades de la Unión Industrial y la fecha tardía en que inició la compra-venta de fincas hizo que el grueso de las mismas se encaminase a operaciones de descuento y negociación de letras. Esta función intermediadora se ratificó a partir de su vinculación con el Banco de Madrid.

Su quiebra y liquidación es igualmente representativa. Fue consecuencia de las dificultades que attravesaton otras entidades - la Sociedad de Descuentos, su sucursal en Valencia-. Sufrió la huida masiva de impositores, estrangulando desde entonces su vía fundamental de ingresos. Y padeció el desajuste entre una proyección inmobiliaria iniciada a precios onerosos, la brusca caída de la demanda y la quiebra de la cadena que aseguraba los intereses de los créditos hipotecarios concedidos. A pesar de que el capítulo de su crisis se inició en una fecha temprana (1865), su pasivo concentrado en imposiciones amortizables, la inexistencia de ninguna garantía real por parte del Banco y su activo de problemática realización impidió que su situación pudiese ser saneada. 